\title{
Changes of Motor Function according to Attention Differences in Stroke Patients: A Randomized Controlled Trial, Pilot Study
}

\author{
Sun-Young $\mathrm{Ha}^{1} \mathrm{PhD}$, Yun-Hee Sung ${ }^{1,2} \mathrm{PhD}$ \\ ${ }^{1}$ Department of Physical Therapy, Graduate School, Kyungnam University, Changwon; ${ }^{2}$ Department of Physical Therapy, College of Health Sciences, Kyungnam \\ University, Changwon, Korea
}

PURPOSE: The purpose of this study was to investigate the changes of electroencephalography (EEG) activity on balance and gait while physiotherapy in stroke patients.

METHODS: General physiotherapy was applied to 18 stroke patients for 30 minutes per session, 5 times a week, for a total 4 weeks. EEG measured for one week while intervention. Based on the attention score, group was classified into high and low attention groups. We used functional reaching test to measure dynamic balance and GAITRite to measure spatiotemporal variables during gait.

RESULTS: In the high attention group, the sensorimotor rhythm wave was high and the dynamic balance was significantly increased $(p<.05)$. There were significant differences in stance time, single support time, and double support time among temporal variables $(p<.05)$. There were significant differences in step length, stride length, swing \% of cycle, stance \% of cycle, single support \% of cycle, and double support \% of cycle among the spatial gait variables $(p<.05)$.

CONCLUSIONS: The high attention during physiotherapy helps improvement of balance and gait ability in stroke patients, therefore, it may be considered in intervention.

Key words: Electroencephalography, Attention, Balance, Gait, Stroke

\section{INTRODUCTION}

Stroke means that blood supply to the brain nerve cells is stopped due to cerebrovascular ischemia and hemorrhage. This causes neural cells in certain brain areas to be necrotic [1]. This results in impaired cognitive function, and problems with attention, memory, and executive function [2]. Among them, attention problem of stroke patients is one of the most frequently reported symptoms [3], and the decrease of attention eventually leads to the limitation in daily life [4]. In particular, the dysfunction on balance and gait appear to be the main problems of stroke patients [5]. Sustained decrease in attention not only results in motor performance [6], but also causes various damages in daily life [7]. Therefore, attention is an important factor for the recovery of impaired motor function in stroke patients [8].

Electroencephalography (EEG) is mainly used to measure neurophysi- ological changes in the brain [9], and is divided into delta, theta, alpha, beta, and gamma waves. Among them, the beta waves corresponds to 12 to $35 \mathrm{~Hz}$, and is subdivided into sensorimotor rhythm (SMR) wave (12 to $15 \mathrm{~Hz}$ ), mid beta wave (15 to $18 \mathrm{~Hz}$ ), and high beta wave (20 to $35 \mathrm{~Hz}$ ) SMR waves are observed while solving simple problems or focusing to external stimuli. And it plays a role in improving cognitive ability and awareness of the body [10]. In stroke patients, alpha and beta waves decrease due to reduced attention ability, and delta and theta waves increase. Therefore, restoration of the SMR waves in stroke patients means improvement of attention.

Interventions such as neurofeedback training and action observation training have been reported to improve the concentration of brain injured patients [11-14]. These interventions have been reported to improve motor function through improved concentration, but the application of these interventions in clinical practice is not easy [6]. Furthermore, in

Corresponding author: Yun-Hee Sung Tel +82-55-249-6334 Fax+82-05059992173 E-mail sungpt97akyungnam.ac.kr

Received 18 May 2020 Revised 21 Jun 2020 Accepted 29 Jun 2020

@)This is an Open Access article distributed under the terms of the Creative Commons Attribution Non-Commercial License (https://creativecommons.org/licenses/by-nc/4.0/) which permits unrestricted non-commercial use distribution, and reproduction in any medium, provided the original work is properly cited. 
previous studies, concentration was measured during stability, not during exercise. In clinical practice, most therapists tend to emphasize improvement of only motor function without considering attention although there are various interventions that can improve attention with motor function [15]. Therefore, we investigated effects of motor function on attention during intervention in stroke patients.

\section{METHODS}

\section{Participants}

This study was conducted in stroke patients who were hospitalized at $\mathrm{H}$ hospital. The inclusion criteria were 1) those who are diagnosed with a stroke, 2) those who have passed 6 months or more from the onset period, 3) those who have a score of 24 or higher on the Mini Mental State Examination- Korea, 4) those who can walk more than $4 \mathrm{~m}$ independently or assistive devices. The exclusion criteria are 1) those with unilateral neglect, 2) those with visual perception problems, 3) those with communication and motor learning limitations, 4) those with musculoskeletal and cardiovascular diseases. All participants were informed and agreed to the experiment. After pre-test, general physiotherapy (trunk strengthening and gait training) were applied twice a day, five times a week, for a total four weeks. EEG was collected for one week. All test measured before and after intervention (Fig. 1). The present study was approved by Kyungnam University Ethics Committee (number: 1040460-A-2019-003).

\section{Mini-mental state examination-Korea (MMSE-K)}

This is a tool for evaluating the cognitive status of the patient in areas

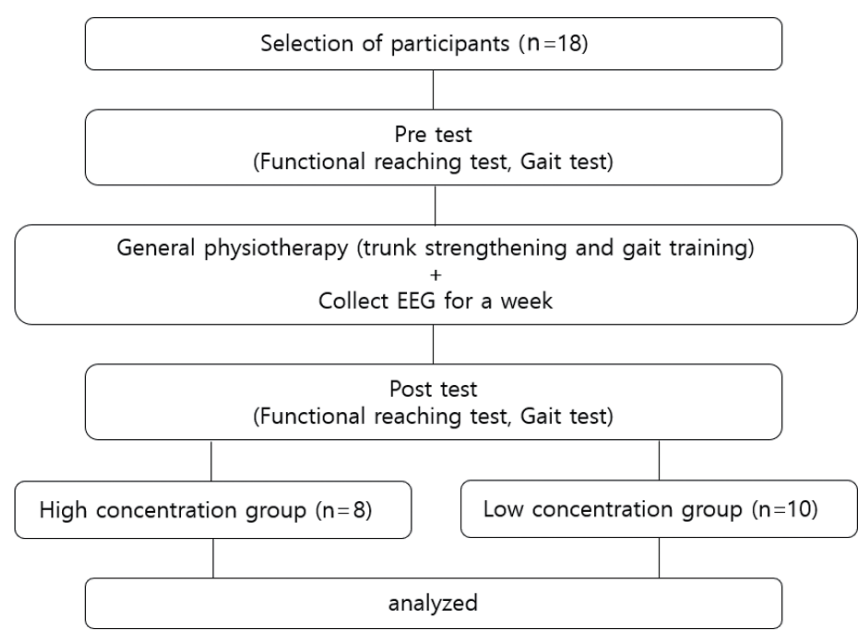

Fig. 1. Flow chart. such as orientation, memory registration, attention and calculation, memory recall, language and judgment ability. The highest score is 30 , the lowest score is 0 , and more than 24 is normal. The test-retest and inter-rater reliability were of 0.91 and 0.99 respectively [16].

\section{Electroencephalography}

The Neuro Sky ${ }^{\circledR}$ MindWave Mobile headset (NeuroSky Inc., CA, USA) was used to measure attention of stroke patients. The device consists of a single dry electrode $(12 \mathrm{~mm} \times 16 \mathrm{~mm})$ placed on Fpl according to the international 10-20 system. Participants put on an EEG headset with the active electrode placed on the left forehead and the reference electrode clipped to their left earlobe. Noise frequencies due to eye blink and muscle activity were automatically eliminated using proprietary algorithms. The sampling rate was $512 \mathrm{~Hz}$, and the raw EEG signal was transmitted via Bluetooth to the NeuroView software installed on the computer. We collected primitive EEG from 0 to $50 \mathrm{~Hz}$ and attention and meditation index. Among the collected data, if attention index is higher than 50, it is classified into a high attention group, and if it is lower than 50, it is classified into a low attention group. After obtaining the EEG power for each frequency band, a relative power analysis was performed on the frequency calculated by the band power.

Relative band power $(\mathrm{RBP})=$ specific frequency area/overall frequency area $(5-50 \mathrm{~Hz})$.

\section{Gait}

GAITRite (GAITRite, CIR system Inc., USA) was used to measure the spatial and temporal variables on gait. It is an electronic walking board 5 $\mathrm{m}$ long, $61 \mathrm{~cm}$ wide and $0.6 \mathrm{~cm}$ high, and transmits walking data to a computer. The participants were placed in front of the walkway and then walked at a comfortable walking speed by the examiner's verbal signal to exit the walkway. Information about temporal and spatial variables is collected by the pressure applied to the sensor as the participant walks the walkway, and the average value is used by measuring three times.

\section{Functional reaching test (FRT)}

FRT was used to evaluate the dynamic balance. Participants place their feet shoulder-width apart in a standing position by the wall, and bend the shoulder joint 90 degrees with the non-affected side arm fully extended forward. Then, the movement distance of the tip of the third finger was measured by bending the trunk forward without moving the foot, and the average value is used by measuring three times [17]. 


\section{Statistical analysis}

SPSS version 18.0 was used for statistical analysis. The KomogrovSmirnov test was conducted for the normality test. The independent ttest was performed to determine the differences between groups of variables, and the paired $t$-test was performed to determine the differences within the group. The significance level was 0.05 .

\section{RESULTS}

\section{General characteristics}

The general characteristics of the participants are shown in Table 1 ,

Table 1. General characteristics of participants

\begin{tabular}{lccc}
\hline & HAG $(\mathrm{n}=8)$ & LAG $(\mathrm{n}=10)$ & $p$ \\
\hline Gender (M/F) & $4 / 4$ & $4 / 6$ & \\
Age $(\mathrm{yr})$ & $70.75 \pm 14.39$ & $63.40 \pm 16.67$ & .339 \\
weight $(\mathrm{kg})$ & $59.50 \pm 1.19$ & $66.20 \pm 12.34$ & .059 \\
height $(\mathrm{cm})$ & $158.25 \pm 4.43$ & $165.10 \pm 8.64$ & .148 \\
paretic side (Rt/Lt) & $4 / 4$ & $4 / 6$ &
\end{tabular}

HAG, high attention group; LAG, low attention group.

Table 2. Comparison of EEG activity

\begin{tabular}{lccc}
\hline WAVE & HAG & LAG & $p$ \\
\hline ALPHA & $0.07 \pm 0.02$ & $0.12 \pm 0.02$ & $.000^{*}$ \\
SMR & $0.44 \pm 0.09$ & $0.15 \pm 0.03$ & $.000^{*}$ \\
MID BETA & $0.05 \pm 0.02$ & $0.08 \pm 0.01$ & $.002^{*}$ \\
\hline
\end{tabular}

${ }^{*} p<.05$.

EEG, electroencephalography; SMR, sensorimotor rhythm; HAG, high attention group; LAG, low attention group. and there is no statistically significant difference between the groups $(p>.05)$.

\section{EEG activity}

Alpha, SMR, and mid beta waves showed significant difference between the groups $(p<.05)$ (Table 2$)$.

\section{Dynamic balance}

The high attention group showed a significant difference $(p<.05)$, but the low attention group showed no significant difference $(p>.05)$. There was a significant difference in the amount of change (post-pre) between the groups $(p<.05)$ (Table 3$)$.

\section{Temporal variables on gait}

In the high attention group, stance time, single support of time, and double support of time were significant difference within the group $(p<.05)$, but the low attention group was not significant difference

Table 3. Comparison of FRT

\begin{tabular}{lccc}
\hline & HAG & LAG & $p$ \\
\hline pre & $17.95 \pm 3.89$ & $16.63 \pm 6.75$ & .596 \\
post & $23.44 \pm 8.17$ & $17.29 \pm 0.38$ & .086 \\
post-pre & $5.49 \pm 6.29$ & $0.65 \pm 2.49$ & $.043^{*}$ \\
$p$ & $.022^{*}$ & .403 & \\
\hline
\end{tabular}

${ }^{*} p<.05$.

FRT, functional reaching test; HAG, high attention group; LAG, low attention group.

Table 4. Comparison of temporal variables of the non-affected side leg

\begin{tabular}{llccc}
\hline variables & & HAG & LAG & $p$ \\
\hline swing time (sec) & pre & $0.40 \pm 0.06$ & $0.49 \pm 0.15$ & .106 \\
& post & $0.40 \pm 0.05$ & $0.44 \pm 0.13$ & .444 \\
& post-pre & $0.00 \pm 0.01$ & $-0.05 \pm 0.18$ & .370 \\
& $p$ & .555 & .38 & $.91 \pm 0.79$ \\
stance time (sec) & pre & $1.17 \pm 0.32$ & $1.93 \pm 0.09$ & $.014^{*}$ \\
& post & $1.05 \pm 0.20$ & $0.02 \pm 0.53$ & $.009^{*}$ \\
& post-pre & $-0.12 \pm 0.12$ & .885 & .425 \\
single support of & $p$ & $.010^{*}$ & $0.55 \pm 0.17$ & .273 \\
time (sec) & pre & $0.49 \pm 0.07$ & $0.55 \pm 0.20$ & .537 \\
& post & $0.51 \pm 0.08$ & $0.00 \pm 0.15$ & .583 \\
double support of & post-pre & $0.03 \pm 0.02$ & .984 & $.15 \pm 0.81$ \\
time (sec) & $p$ & $.008^{*}$ & $1.39 \pm 0.75$ & $.004^{*}$ \\
& pre & $0.59 \pm 0.13$ & $-0.12 \pm 0.51$ & $.002^{*}$ \\
& post & $0.47 \pm 0.05$ & .473 \\
\hline
\end{tabular}

${ }^{*} p<.05$.

HAG, high attention group; LAG, low attention group. 
( $p>.05)$. Stance time and double support of time were significant difference between the groups $(p<.05)$ (Table 4$)$.

\section{Spatial variables on gait}

In the high attention group, step length, stride length, swing\% of cycle, stance $\%$ of cycle, single support $\%$ of cycle, and double $\%$ of cycle were significant difference within the group $(p<.05)$, but low attention group was not significant difference ( $p>.05)$. Swing $\%$ of cycle, stance $\%$ of cycle, single support $\%$ of cycle, and double\% of cycle were significantly different between groups after intervention $(p<.05)$, and the stride length, swing\% of cycle, and single support $\%$ of cycle were significantly different the amount of change (post-pre) between the groups $(p<.05)$ (Table 5).

\section{DISCUSSION}

EEG shows a specific pattern according to the state of consciousness, mental activity, and brain disease, so it is used as a main means of evaluating cerebral function $[18,19]$. Among the EEG, beta waves increase in arousal state and cognitive activity for active problem solving. Of beta waves, SMR waves increase in performance tasks that require attention. Stroke patients abnormally decrease alpha and SMR waves compared to normal people and increase theta waves [20,21]. A decrease of theta waves means a recovery of EEG pattern likely normal EEG in stroke patients [20]. The SMR wave activity while physical therapy means high concentration. While performing tasks that require attention, alpha waves are suppressed and beta waves increase [22]. Keller (2001) reported improved concentration when beta-wave activation training was applied to patients with traumatic brain injury with reduced concentration. This is because the activity of beta waves corresponds to the improved continuous attention task data [12]. In addition, Rozelle \& Budzynski (1995) reported that concentration improved after beta-wave activation training [23]. Activation of beta waves means an improvement in concentration, it eventually affected motor function and activity of daily life [24] (Kado et al., 2002). In the present study, we also found that SMR waves were significantly higher in the high attention group than in the low attention group. Furthermore, it can be assumed that high concentration will affect motor function improvement.

Balance control is the basis for independent locomotion and func-

Table 5. Comparison of spatial variables of the non-affected side leg

\begin{tabular}{|c|c|c|c|c|}
\hline variables & & HAG & LAG & $p$ \\
\hline \multirow[t]{4}{*}{ step length $(\mathrm{cm})$} & pre & $27.24 \pm 4.98$ & $27.84 \pm 8.84$ & .853 \\
\hline & post & $31.73 \pm 1.72$ & $29.85 \pm 9.80$ & .544 \\
\hline & post-pre & $4.49 \pm 4.67$ & $2.01 \pm 6.19$ & .317 \\
\hline & $p$ & $.014^{*}$ & .307 & \\
\hline \multirow[t]{4}{*}{ stride length $(\mathrm{cm})$} & pre & $60.87 \pm 4.84$ & $61.00 \pm 17.84$ & .982 \\
\hline & post & $69.85 \pm 5.57$ & $61.63 \pm 19.85$ & .213 \\
\hline & post-pre & $8.98 \pm 5.39$ & $0.63 \pm 8.99$ & $.020^{*}$ \\
\hline & $p$ & $.001^{*}$ & .821 & \\
\hline \multirow[t]{4}{*}{ swing $\%$ of cycle } & pre & $26.20 \pm 4.29$ & $22.88 \pm 8.27$ & .260 \\
\hline & post & $29.55 \pm 3.15$ & $22.10 \pm 7.80$ & $.011^{*}$ \\
\hline & post-pre & $3.35 \pm 3.62$ & $-0.78 \pm 3.76$ & $.019^{*}$ \\
\hline & $p$ & $.017^{*}$ & .506 & \\
\hline \multirow[t]{4}{*}{ stance $\%$ of cycle } & pre & $73.78 \pm 4.26$ & $77.11 \pm 8.29$ & .268 \\
\hline & post & $72.05 \pm 3.60$ & $77.90 \pm 7.79$ & $.041^{*}$ \\
\hline & post-pre & $-1.73 \pm 0.98$ & $0.79 \pm 3.77$ & .055 \\
\hline & $p$ & $.000^{*}$ & .502 & \\
\hline \multirow[t]{4}{*}{ single support $\%$ of cycle } & pre & $32.46 \pm 6.82$ & $24.99 \pm 9.52$ & .055 \\
\hline & post & $37.42 \pm 6.59$ & $24.25 \pm 6.34$ & $.000^{*}$ \\
\hline & post-pre & $4.96 \pm 2.59$ & $-0.74 \pm 6.35$ & $.016^{*}$ \\
\hline & $p$ & $.000^{*}$ & .709 & \\
\hline \multirow[t]{4}{*}{ double support $\%$ of cycle } & pre & $38.20 \pm 4.51$ & $58.06 \pm 15.76$ & $.002^{*}$ \\
\hline & post & $33.13 \pm 4.84$ & $54.25 \pm 13.55$ & $.000^{*}$ \\
\hline & post-pre & $-5.07 \pm 2.41$ & $-3.81 \pm 10.48$ & .714 \\
\hline & $p$ & $.000^{*}$ & .256 & \\
\hline
\end{tabular}

${ }^{*} p<.05$.

HAG, high attention group; LAG, low attention group. 
tional movement [25]. Decreased balance is associated with impaired cognitive function [26], as well as neuromuscular and musculoskeletal factors [27-29]. Therefore, attention is essential for maintaining balance [30-32]. Silsupadol et al. (2009) reported that tasks (single-task training; dual-task training with fixed-priority instruction; dual-task training with variable-priority instruction) requiring attention improve balance ability in the elderly people with poor balance [33]. Verheyden et al. (2006) mentioned that intervention enhancing trunk control with attention improves balance and gait in stroke patients [5]. Our results also showed that the high attention group had improvement of the dynamic balance ability and gait.

Gait is one of the most important functions in determining the level of independence and quality of life [34]. Damaged brain results in abnormal gait patterns. In stroke patients, of gait parameters, double limb support increases, velocity and swing phase on the non-affected side decreases [35]. Plummer-D’Amato et al. (2007) reported positive effects on velocity, stride length and cadence applying gait training with three cognitive tasks in stroke patients [36]. Lee et al. (2015) showed that gait ability (velocity, cadence, stance phase) was improved in the group treated neurofeedback training with visual stimulation in stroke patients [11]. They mentioned that attention from the intervention was a secondary factor mediating the change of gait. Also, in our results, gait ability was enhanced in high attention group, despite providing the same interventions to the participants.

This study was to investigate the effect of concentration on gait and balance during physical therapy. We found that balance and gait were improved in the high concentration group. Through our results, we could know whether or not to concentrate during intervention, and the higher the concentration, the better the motor function. Therefore, it is necessary to consider the concentration factor in intervention, and in the future studies, studies on intervention applicable in clinical practice should be conducted to increase concentration. The limitations of this study were a small number of participants and a limitation in generalizing the results. In future studies, studies should be conducted to compensate for these limitations.

\section{CONFLICT INTEREST}

The authors declare no conflicts of interest.

\section{ORCID}

Sun-Young Ha https://orcid.org/0000-0001-7715-9579

Yun-Hee Sung https://orcid.org/0000-0002-4877-9784

\section{REFERENCES}

1. Cauraugh JH, Kim S. Two coupled motor recovery protocols are better than one: electromyogram triggered neuromuscular stimulation and bilateral movements. Stroke. 2002;33(6):1589-94.

2. Kalaria RN, Ballard C. Stroke and cognition. Curr Atheroscler Rep. 2001;3(4):334-9.

3. Cicerone KD. Attention deficits and dual task demands after mild traumatic brain injury. Brain Inj. 1996;10(2):79-89.

4. Hyndman D, Ashburn A. People with stroke living in the community: attention deficits, balance, ADL ability and falls. Disabil Rehabil. 2003;25(15):817-22.

5. Verheyden G, Vereeck L, Truijen S, Troch M, Herregodts I, et al. Trunk performance after stroke and the relationship with balance, gait and functional ability. Clin Rehabil. 2006;20(5):451-8.

6. McEwen SE, Huijbregts MP, Ryan JD, Polatajko HJ. Cognitive strategy use to enhance motor skill acquisition post-stroke: a critical review. Brain Inj. 2009;23(4):263-77.

7. Gontkovsky ST, McDonald NB, Clark PG, Ruwe WD. Current directions in computer-assisted cognitive rehabilitation. NeuroRehabilitation. 2002;17(3):195-9.

8. Guadagnoli MA, Lee TD. Challenge point: a framework for conceptualizing the effects of various practice conditions in motor learning. J Mot Behav. 2004;36(2):212-24.

9. Florence G, Guerit JM, Gueguen B. Electroencephalography (EEG) and somatosensory evoked potentials (SEP) to prevent cerebral ischaemia in the operating room. Neurophysiol Clin. 2004;34(1):17-32.

10. Egner T, Gruzelier JH. Learned self-regulation of EEG frequency components affects attention and event-related brain potentials in humans. Neuroreport. 2001;12(18):4155-9.

11. Lee YS, Bae SH, Lee SH, Kim KY. Neurofeedback training improves the dual-task performance ability in stroke patients. Tohoku J Exp Med. 2015;236(1):81-8.

12. Keller. Neurofeedback Therapy of Attention Deficits in Patients with Traumatic Brain Injury. J Neurother. 2001;5(1/2):19-32.

13. Rizzolatti G, Fogassi L, Gallese V. Neurophysiological mechanisms un- 
derlying the understanding and imitation of action. Nat Rev Neurosci. 2001;2(9):661-70

14. Buccino G, Binkofski F, Riggio L. The mirror neuron system and action recognition. Brain Lang. 2004;89(2):370-6.

15. Michel JA, Mateer CA. Attention rehabilitation following stroke and traumatic brain injury. A review. Eura Medicophys. 2006;42(1):59-67.

16. Kwon YC, Park JH. Korean Version of Mini-Mental State Examination (MMSE-K) Part I: developement of the test for the elderly. J Korean Neuropsychiatr Assoc. 1989;28(1):125-35.

17. Duncan PW, Weiner DK, Chandler J, Studenski S. Functional reach: a new clinical measure of balance. J Gerontol. 1990;45(6):192-7.

18. Kim YK, Jang NK. Changes of the prefrontal EEG (Electroencephalogram) activities according to the repetition of audio-visual learning. J Korea Assoc Sci Edu. 2001;21(3):516-28.

19. Rodriguez E, George N, Lachaux JP, Martinerie J, Renault B, et al. Perception's shadow: long-distance synchronization of human brain activity. Nature. 1999;397(6718):430-3.

20. Bearden TS, Cassisi JE, Pineda M. Neurofeedback training for a patient with thalamic and cortical infarctions. Appl Psychophysiol Biofeedback. 2003;28(3):241-53.

21. Bentes C, Peralta AR, Viana P, Martins H, Morgado C, et al. Quantitative EEG and functional outcome following acute ischemic stroke. Clin Neurophysiol. 2018;129(8):1680-7.

22. Fairclough SH, Venables L, Tattersall A. The influence of task demand and learning on the psychophysiological response. Int J Psychophysiol. 2005;56(2):171-84.

23. Rozelle GR, Budzynski TH. Neurotherapy for stroke rehabilitation: a single case study. Biofeedback Self Regul. 1995;20(3):211-28.

24. Cho HY, Kim KT, Jung JH. Effects of computer assisted cognitive rehabilitation on brain wave, memory and attention of stroke patients: a randomized control trial. J Phys Ther Sci. 2015;27(4):1029-32.

25. Melzer I, Benjuya N, Kaplanski J, Alexander N. Association between ankle muscle strength and limit of stability in older adults. Age Ageing. 2009;38(1):119-23

26. Fjeldstad C, Pardo G, Bemben D, Bemben M. Decreased postural balance in multiple sclerosis patients with low disability. Int J Rehabil Res. 2011;34(1):53-8.

27. Cattaneo D, Jonsdottir J. Sensory impairments in quiet standing in subjects with multiple sclerosis. Mult Scler. 2009;15(1):59-67.

28. Cameron ID, Dyer SM, Panagoda CE, Murray GR, Hill KD, et al. Interventions for preventing falls in older people in care facilities and hospitals. Cochrane Database Syst Rev. 2018;9(9):CD005465.

29. Soyuer F, Mirza M, Erkorkmaz U. Balance performance in three forms of multiple sclerosis. Neurol Res. 2006;28(5):555-62.

30. Marsh AP, Geel SE. The effect of age on the attentional demands of postural control. Gait Posture. 2000;12(2):105-13.

31. Lajoie Y, Teasdale N, Bard C, Fleury M. Attentional demands for static and dynamic equilibrium. Exp Brain Res. 1993;97(1):139-44.

32. Teasdale JD. Emotion and two kinds of meaning: cognitive therapy and applied cognitive science. Behav Res Ther. 1993;31(4):339-54.

33. Silsupadol P, Shumway-Cook A, Lugade V, van Donkelaar P, Chou LS, et al. Effects of single-task versus dual-task training on balance performance in older adults: a double-blind, randomized controlled trial Arch Phys Med Rehabil. 2009;90(3):381-7.

34. Turnbull GI, Charteris J, Wall JC. A comparison of the range of walking speeds between normal and hemiplegic subjects. Scand J Rehabil Med. 1995;27(3):175-82.

35. Tanaka H, Nankaku M, Nishikawa T, Hosoe T, Yonezawa H, et al. Spatiotemporal gait characteristic changes with gait training using the hybrid assistive limb for chronic stroke patients. Gait Posture. 2019; 71:205-10.

36. Plummer-D’Amato P, Altmann LJ, Saracino D, Fox E, Behrman AL, et al. Interactions between cognitive tasks and gait after stroke: a dual task study. Gait Posture. 2008;27(4):683-8. 